\title{
Uso de pronomes no texto "Sendbrief von Dolmetschen" de Martinho Lutero
}

\section{Use of pronouns in Martin Luther's text "Sendbrief von Dolmetschen"}

Dachamir Hotza*

Universidade Federal de Santa Catarina

\begin{abstract}
RESUMO: Este artigo apresenta uma análise sobre o uso de pronomes no texto "Sendbrief von Dolmetschen" ("Carta aberta sobre a tradução"), escrito originalmente por Martinho Lutero na Alemanha, em 1530. O objetivo é tentar identificar, a partir da frequência e localização do uso dos pronomes nesse texto, o(s) destinatário(s) a que Lutero se refere. Na questão sobre a justificativa pela fé, há claramente um debate de ideias entre Lutero e seus opositores ("eu" contra "eles"). Já na questão sobre a intercessão dos santos, o texto se dirige prioritariamente aos seus seguidores (uso destacado de "nós"). Conclui-se que não há apenas um destinatário, mas vários que se destacam ao longo do texto.
\end{abstract}

PALAVRAS-CHAVE: Lutero; pronomes; tradução.

ABSTRACT: This article presents an analysis about the use of pronouns in the text "Sendbrief von Dolmetschen" ("Open letter on translating") originally written by Martin Luther in Germany in 1530. The objective is to try to identify the addressee(s) referred by Luther from frequency and location of pronouns use in this text. Regarding the question about justification by belief, there is clearly a debate of ideas between Luther and his opponents ("I" against "them"). When the question about the intercession of saints is concerned, the text is directed to his followers (noticeable use of "we"). It is concluded that there is not a single addressee, but many of them, which are highlighted along the text.

KEYWORDS: Luther; pronouns; translation.

\section{Introdução}

Martinho Lutero, cujo nome em alemão era Martin Luther, nasceu em 1483 em Eisleben, Alemanha. Em 1501, ingressou na Universidade de Erfurt, onde se graduou bacharel em 1502 e concluiu o mestrado em 1505. Nesse mesmo ano, Lutero entrou para a ordem dos Agostinianos, também em

*dhotza@gmail.com 
Erfurt. Em 1507, foi ordenado sacerdote e em 1512 graduou-se Doutor em Teologia pela Universidade de Wittenberg. Durante esse período, Lutero estudou grego e hebraico, para aprofundar-se no significado e origem das palavras utilizadas nas Escrituras - conhecimentos que logo utilizaria para a sua própria tradução da Bíblia (SCHWIEBERT, 1950).

Em 1517, publicou em Wittenberg suas 95 Teses, em latim, condenando as indulgências na Igreja Católica, suscitando um amplo debate teológico. Em 1521, foi excomungado pelo Papa Leão X. Nesse ano, Lutero foi ouvido na Dieta de Worms e, após ter negado a revogação da sua doutrina, foi exilado no Castelo de Wartburg. Durante cerca de 10 meses de retiro forçado, trabalhou na sua célebre tradução da Bíblia para o alemão (BRECHT, 1993).

No outono de 1521, em apenas 11 semanas, Lutero traduziu o Novo Testamento do grego para o alemão. Como modelo, empregou a edição do Novo Testamento Grego publicada em 1516 por Erasmo de Roterdã, que incluía uma tradução em latim e anotações críticas. Para esse ofício, usou também a Vulgata, escrita em meados do século IV por São Jerônimo. O Novo Testamento de Lutero foi publicado em setembro de 1522. A partir de 1523, uma parte do Antigo Testamento traduzido também foi acrescida à sua obra. Em 1534, foi lançada a tradução completa do Antigo Testamento Hebraico para o alemão. Ambos os Testamentos compõem a famosa Bíblia de Lutero (BAINTON, 1995).

A tradução de Lutero da Bíblia tornou as Escrituras mais acessíveis para o povo comum, e teve um enorme impacto político sobre a Igreja e sobre a cultura alemã. Incentivou o desenvolvimento de uma versão padrão da língua alemã, acrescentou vários princípios à técnica de tradução e influenciou outras traduçôes da Bíblia para línguas vernáculas.

Da prolífica obra de Lutero, destacam-se dois textos clássicos que expõem o seu pensamento a respeito da tradução: Sendbriefvom Dolmetschen ("Carta aberta sobre a tradução") (LUTHER, 2006a) e Summarien über die Psalmen und Ursachen des Dolmetschens ("Comentários sobre os salmos e os motivos da tradução”) (LUTHER, 2006b), escritos respectivamente em 1530 e 1531. Esses textos apresentam não apenas sua concepção da tradução mas também alguns pontos centrais de sua teologia.

A "Carta aberta sobre a tradução", em particular, constitui uma resposta a questôes concernentes ao processo de tradução utilizado por Lutero. A característica básica de seu estilo de traduzir é a ênfase na língua de chegada, admitindo, porém, estrangeirismos se a formulação do original expressa 
melhor o conteúdo da mensagem. Seu estilo inovador, no entanto, não se furtou a críticas (FURLAN, 2002).

Este artigo pretende desenvolver uma análise contextual com base no uso de pronomes em Sendbrief vom Dolmetschen. Para tanto, serão considerados como corpus o texto original de Lutero, bem como uma tradução disponível em português brasileiro. $\mathrm{O}$ objetivo é tentar identificar, a partir da frequência e localização do uso dos pronomes nesse texto, o(s) destinatário(s) a que Lutero se refere.

\section{O texto original}

Para a elaboração deste artigo, foram consultadas duas versões do texto em alemão de Lutero: uma fac-símile do texto publicado em Weimar em 1909 (LUTHER, 1909), reproduzida no livro de Bocquet em 2000 (BOCQUET, 2000), bem como uma versão em alemão atualizado disponibilizada por Sochorek, a partir de 1999 (LUTHER, [s. d.]), reproduzida por Furlan (FURLAN, 2002).

\section{Notas introdutórias}

O texto principal (LUTHER, 1909) é composto por 39 parágrafos em alemão e é assinado e datado por Lutero: Ex Eremo octva Septembris 1530 ("Do exílio, 8 de setembro de 1530) (LUTHER, 1909). Nesse período, Lutero se encontrava recluso no Castelo de Coburg.

O texto é precedido de uma carta em latim endereçada a Wenzeslaus Link (BOCQUET, 2000), seu amigo que vivia em Nurenberg. Tal como Lutero, Link se tornou monge agostiniano e doutor em Teologia, também em Wittenberg, em 1511, um ano antes de Lutero. Ambos deixaram o convento para se casar: Link em 1523 e Lutero em 1525 (BOCQUET, 2000).

$\mathrm{Na}$ carta introdutória, datada de 12 de setembro de 1530, Lutero solicita a Link a publicação de seu texto e sugere que este seja intitulado Ein Sendbrief von Dolmetschen ("Uma carta aberta sobre a tradução"). No texto publicado em alemão, constante da edição de Weimar (LUTHER, 1909; LUTHER, [s. d.]), há um parágrafo a título de prefácio, escrito por Link, em Nurenberg, direcionado a "todos os fiéis cristãos" (allen Christgläubigen), datado de 15 de setembro de 1530 .

Link é o receptor da Carta, entretanto, não é o seu destinatário (BOCQUET, 2000). A Carta é dirigida a um correspondente cuja identidade 
se oculta sob uma inicial: Dem ehrbaren und umsichtigen N., meinem geneigten Herrn und Freunde ("Ao honorável e distinto N., meu estimado senhor e amigo") (LUTHER, 2006a). Não se sabe se a Carta responde à perguntas verdadeiramente formuladas por esse correspondente, que talvez nem tenha existido na realidade (GARCIA YEBRA, 1979).

\section{A estrutura do texto}

Sendbriefvom Dolmetschen se apresenta como resposta a duas questóes que foram colocadas a Lutero: a primeira diz respeito à tradução do versículo 28 do capítulo 3 da Epístola aos Romanos, e a segunda trata da intercessão dos santos (BOCQUET, 2000).

Naturalmente, no entanto, a questão de fé transcende a questão tradutológica, a começar pela colocação no parágrafo introdutório:

... warum ich [...] die Worte Sankt Pauli: "Arbitramur hominem iustificari ex fide absque operibus" also verdeutscht habe: "Wir halten, daß der Mensch gerecht werde ohn des Gesetzes Werke, allein ${ }^{1}$ durch den Glauben..."

... por que eu [...] traduzi as palavras de Paulo, Arbitramur hominem iustificari ex fide absque operibus, como "Sustentamos que o homem é justificado somente ${ }^{1}$ pela fé, sem as obras da lei...” (LUTHER, 2006a, $\$ 2)$.

A discussão que se segue em torno da validade ou não do acréscimo da palavra allein/sola ("somente"), não é mera questão estilística de tradução, mas, sem dúvida, uma questão central na doutrina de Lutero: a salvação pela fé, somente, independentemente das obras.

O texto pode ser dividido em seis partes, a saber:

- Parágrafo 1, saudação inicial (“Ao Sr. N.”)

- Parágrafo 2, introdução (apresentação das duas questôes iniciais)

- Parágrafos 3 ao 21, resposta à primeira questão (problema tradutológico)

- Parágrafos 22 ao 27, resposta à primeira questão (problema teológico)

- Parágrafos 28 ao 35, resolução da segunda questão (problema teológico)

- Parágrafos 36 ao 39, despedida (data, local, assinatura, saudação final).

${ }^{1}$ Grifo do autor. 
Os limites de cada parte do texto estão bem demarcados por Lutero:

Auf die erste Frage, wo es euch gelüstet, mögt ihr euern Papisten von meinetwegen antworten also:

“... À primeira pergunta, se desejarem, podem responder aos papistas de minha parte o seguinte: ...” (LUTHER, 2006a, \$2).

Das sei vom Dolmetschen und der Art der Sprachen gesagt. Aber nun [...] bin ihr gefolget, daßich [...] der Text und die Meinung Sankt Pauli fordern und erzwingen's mit Gewalt; denn er behandelt ja daselbst das Hauptstück christlicher Lehre, nämlich, daß wir durch den Glauben an Christum, ohn alle Werke des Gesetzes gerecht werden.

"Isto é o que havia para ser dito quanto à tradução e à propriedade das línguas. Eu, porém, [...] a observei [...] o texto e o pensamento de São Paulo o exigem e o reclamam com força; pois ele trata ali mesmo do elemento principal da doutrina cristã, ou seja, que nós somos salvos pela fé em Cristo, sem qualquer obra da lei.” (LUTHER, 2006a, \$22).

Auf die andere Frage, ob die verstorbenen Heiligen für uns bitten. Darauf will ich jetzt kürzlich antworten... (LUTHER, [s. d.], \$28).

"Em relação à outra pergunta, se os Santos mortos intercedem por nós, desejo responder agora brevemente..."

O texto completo da Carta em alemão tem cerca de 6000 palavras, assim distribuídas:

- saudação $(0,2 \%)$;

- introdução $(2,3 \%)$;

- primeira questão / tradução (55,9\%);

- primeira questão / teologia (19,2\%);

- segunda questão / teologia $(22,0 \%)$;

- despedida (0,4\%).

Nota-se, portanto, a ênfase na questão tradutológica que justifica, inclusive, o título do documento sugerido por Lutero: "Carta aberta sobre a tradução.”

${ }^{2}$ Tradução do autor. 


\section{A questão tradutológica}

Os problemas relativos ao ato de traduzir são discutidos por Lutero, como visto anteriormente, na terceira parte de seu texto. Os parágrafos relativos a essa discussão estão claramente definidos pelo uso dos termos dolmetschen ("traduzir", no sentido de então) e variantes, bem como verdeutschen (literalmente "alemanizar" ou "traduzir para o alemão"). Os termos aparecem, respectivamente, 27 e 16 vezes. A primeira ocorrência é no parágrafo 2, relativo à introdução das questôes-tema do texto; a última ocorrência se dá no parágrafo 22.

O termo dolmetschen ${ }^{3}$ (e suas variantes Dolmetschen, Dolmetschung, Dolmetscher, verdolmetschen, Verdolmetschen), expressam no alemão moderno a noção de "traduzir oralmente" ou "interpretar". À época de Lutero, no entanto, seu significado era "traduzir" no sentido mais genérico do termo, equivalente ao uso atual de übersetzen ("trans-por" ou "traduzir"). O termo moderno übersetzen (Übersetzung, Übersetzer), aparece somente em $1624 \mathrm{em}$ uma obra de Martin Opitz (GARCIA YEBRA, 1979).

A FIG. 1 mostra a frequência dos termos dolmetschen e verdeutschen (e respectivas variantes), indicando a aleatoriedade da distribuição, justificada, portanto, por questōes estilísticas.

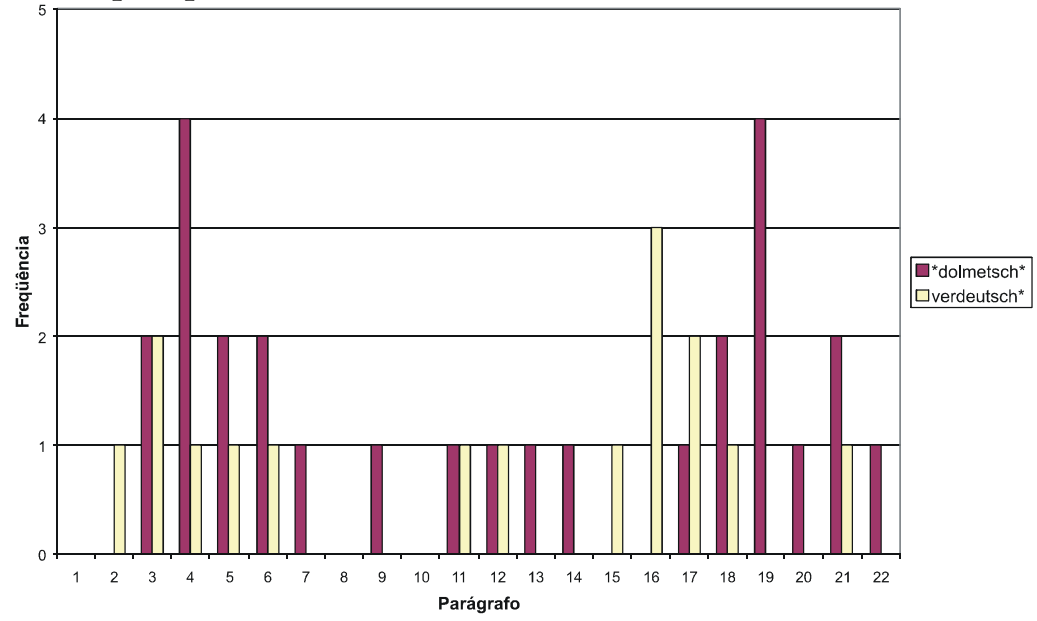

FIGURA 1 - Frequência de ocorrência de termos relativos à tradução na Carta de Lutero

${ }^{3}$ Dolmetschen é um dos poucos empréstimos do húngaro (tolmács) para o alemão. A língua húngara, por sua vez, importou a palavra do turco (dilmaç, hoje entretanto tercüman). Formas comparáveis ocorrem em croata (tumac), polonês (tlumacz) e tcheco (tlumocnik) (BOWEN, 1999). 
TABELA 1 - Frequência de ocorrência de pronomes em Sendbriefvon Dolmetschen de Lutero.

\begin{tabular}{|c|c|c|c|c|c|c|c|c|c|c|c|c|c|}
\hline \multirow{4}{*}{\multicolumn{2}{|c|}{$\begin{array}{c}\text { Pronome } \\
\text { Número } \\
\text { Pessoa } \\
\text { Caso } \\
\text { Alemão } \\
\text { Português }\end{array}$}} & \multirow{3}{*}{\multicolumn{4}{|c|}{$\begin{array}{c}\text { Pessoal } \\
\text { Singular } \\
1^{\text {a }}\end{array}$}} & \multirow{2}{*}{\multicolumn{4}{|c|}{$\begin{array}{l}\text { Pessoal } \\
\text { Singular }\end{array}$}} & \multirow{2}{*}{\multicolumn{4}{|c|}{$\begin{array}{r}\text { Pessoal } \\
\text { Singular } \\
\end{array}$}} \\
\hline & & & & & & & & & & & & & \\
\hline & & & & & & & & 2: & & & & $3^{a}$ & \\
\hline & & \multirow[t]{2}{*}{$\begin{array}{l}\text { Nom. } \\
\text { ich } \\
\text { eu }\end{array}$} & $\begin{array}{c}\text { Acus. } \\
\text { mich } \\
\text { me }\end{array}$ & $\begin{array}{l}\text { Dativo } \\
\text { mir } \\
\text { mim }\end{array}$ & \multirow[t]{2}{*}{$\begin{array}{c}\text { (Gen.) } \\
\text { mein* } \\
\operatorname{meu}(\mathbf{s}) / \\
\operatorname{minha}(\mathbf{s})\end{array}$} & \multirow[t]{2}{*}{$\begin{array}{c}\text { Nom. } \\
\text { du } \\
\text { tu [você] }\end{array}$} & \multirow[t]{2}{*}{$\begin{array}{l}\text { Acus. } \\
\text { dich } \\
\text { te [lhe, } \\
\text { você] } \\
\end{array}$} & \multirow[t]{2}{*}{$\begin{array}{c}\text { Dativo } \\
\text { dir } \\
\text { ti [você] }\end{array}$} & \multirow[t]{2}{*}{$\begin{array}{c}\text { (Gen.) } \\
\text { dein* } \\
\text { teu(s)/tua(s) } \\
{[\text { seu(s)/sua(s)] }}\end{array}$} & \multirow[t]{2}{*}{$\begin{array}{l}\text { Nom. } \\
\text { er/sie } \\
\text { ele/ela }\end{array}$} & \multirow[t]{2}{*}{$\begin{array}{l}\text { Acus. } \\
\text { ihn } / \text { sie } \\
\text { lhe }\end{array}$} & $\begin{array}{c}\text { Dativo } \\
\text { ihm/ihr } \\
\text { ele/ela }\end{array}$ & \multirow[t]{2}{*}{$\begin{array}{c}\text { (Gen.) } \\
\text { sein*/ihr* } \\
\text { seu(s)/ } \\
\text { sua(s) } \\
\end{array}$} \\
\hline Parte & Parágrafos & & & & & & & & & & & & \\
\hline Saudação & 1 & & & & 1 & & & & & & & & \\
\hline Introdução & 2 & 2 & & 1 & 2 & & & & & & & & \\
\hline Questão 1a & 3 a 22 & 104 & 17 & 20 & 34 & 18 & 2 & 1 & & 24 & 3 & 4 & \\
\hline Questão 1b & 23 a 35 & 5 & 2 & 4 & 1 & & & & & 10 & 1 & 4 & \\
\hline Questão 2 & 23 a 35 & 10 & 1 & 2 & 2 & 4 & & & 3 & 7 & & 3 & 2 \\
\hline Despedida & 36 a 39 & & & & 1 & & & & & & & & \\
\hline \multicolumn{2}{|c|}{$\begin{array}{c}\text { Parcial } \\
\text { Total } \\
\text { Percentual } \\
\end{array}$} & 121 & 20 & 27 & $\begin{array}{r}41 \\
209 \\
45,4 \% \\
\end{array}$ & 22 & 2 & 1 & $\begin{array}{c}3 \\
28 \\
6,1 \% \\
\end{array}$ & 41 & 4 & 11 & $\begin{array}{c}2 \\
58 \\
12,6 \% \\
\end{array}$ \\
\hline \multirow{4}{*}{\multicolumn{2}{|c|}{$\begin{array}{c}\text { Pronome } \\
\text { Número } \\
\text { Pessoa } \\
\text { Caso } \\
\text { Alemão } \\
\text { Português }\end{array}$}} & \multicolumn{3}{|c|}{ Pessoal } & Possessivo & \multicolumn{3}{|c|}{ Pessoal } & Possessivo & \multicolumn{3}{|c|}{ Pessoal } & Possessivo \\
\hline & & \multicolumn{4}{|c|}{ Plural } & \multicolumn{4}{|c|}{ Plural } & \multicolumn{4}{|c|}{ Plural } \\
\hline & & \multicolumn{4}{|c|}{$1^{\mathrm{a}}$} & \multicolumn{4}{|c|}{$2^{a}$} & \multicolumn{4}{|c|}{$3^{\mathrm{a}}$} \\
\hline & & $\begin{array}{l}\text { Nom. } \\
\text { wir } \\
\text { nós }\end{array}$ & $\begin{array}{c}\text { Acus. } \\
\text { uns } \\
\text { nos }\end{array}$ & $\begin{array}{c}\text { Dativo } \\
\text { uns } \\
\text { nos }\end{array}$ & $\begin{array}{c}\text { (Gen.) } \\
\text { unser* } \\
\text { nosso(s)/ } \\
\text { nossas(s) }\end{array}$ & $\begin{array}{l}\text { Nom. } \\
\text { ihr } \\
\text { vós } \\
\text { [vocês] }\end{array}$ & $\begin{array}{l}\text { Acus. } \\
\text { euch } \\
\text { vos } \\
\text { [lhes, } \\
\text { vocês] } \\
\end{array}$ & $\begin{array}{l}\text { Dativo } \\
\text { euch } \\
\text { vos } \\
\text { [vocês] }\end{array}$ & $\begin{array}{c}\text { (Gen.) } \\
\text { eur* } \\
\text { vosso(s)/ } \\
\text { vossa(s) } \\
{[\operatorname{seu}(\mathbf{s}) / \operatorname{sua}(s)]} \\
\end{array}$ & $\begin{array}{c}\text { Nom. } \\
\text { sie } \\
\text { eles/ elas }\end{array}$ & $\begin{array}{l}\text { Acus. } \\
\text { sie } \\
\text { lhes }\end{array}$ & $\begin{array}{c}\text { Dativo } \\
\text { ihnen } \\
\text { eles/ elas }\end{array}$ & $\begin{array}{l}\text { (Gen.) } \\
\text { ihr* } \\
\text { seu(s)/ } \\
\text { sua(s) }\end{array}$ \\
\hline Parte & Parágrafos & & & & & & & & & & & & \\
\hline $\begin{array}{l}\text { Saudação } \\
\text { Introdução }\end{array}$ & $\begin{array}{l}1 \\
2\end{array}$ & 2 & & 2 & & 2 & 1 & & 2 & & & & \\
\hline Questão 1a & 3 a 21 & 8 & 3 & & 2 & 1 & 2 & & 1 & 44 & 6 & & 19 \\
\hline Questão 1b & 22 a 27 & 5 & 4 & & 4 & & & & & 11 & & & 2 \\
\hline $\begin{array}{l}\text { Questão } 2 \\
\text { Despedida }\end{array}$ & $\begin{array}{l}28 \text { a } 35 \\
36 \text { a } 39 \\
\end{array}$ & 14 & 6 & 3 & 3 & 3 & & & & 9 & 2 & & 4 \\
\hline \multicolumn{2}{|c|}{$\begin{array}{c}\text { Parcial } \\
\text { Total } \\
\text { Percentual }\end{array}$} & 29 & 13 & 5 & $\begin{array}{c}9 \\
56 \\
12,2 \%\end{array}$ & 6 & 3 & 0 & $\begin{array}{c}3 \\
12 \\
2,6 \%\end{array}$ & 64 & 8 & 0 & $\begin{array}{c}25 \\
97 \\
21,1 \%\end{array}$ \\
\hline
\end{tabular}




\section{O uso de pronomes}

A TAB. 1 sumariza as ocorrências dos pronomes pessoais na Carta de Lutero ao longo dos parágrafos. Estão incluídos os pronomes pessoais, considerando seus respectivos casos (nominativo, acusativo, dativo), bem como os pronomes possessivos. Faz-se uma classificação por número (singular, plural) e pessoa do discurso $\left(1^{a}, 2^{a}, 3^{a}\right)$. Os equivalentes em português são acrescidos para fins de comparação. Comentários sobre aspectos quali e quantitativos expostos na TAB. 1 serão feitos nas próximas seções.

$\mathrm{Na}$ TAB. 1 não estão incluídos os pronomes pessoais neutros (es, es, $i h m$ ), por suas características serem de emprego genérico e indistinto. De qualquer modo, registra-se aqui que sua ocorrência no texto em estudo foi de 116 vezes (67 vezes na forma normal es, e 49 na forma contracta s). Os pronomes de terceira pessoa er/sie, apesar de aparecerem na TAB. 1, não suscitaram uma discussão mais específica. $\mathrm{O}$ pronome formal de uso moderno Sie (e variantes), por sua vez, não foi incluído na TAB. 1, pois os primeiros registros de seu uso são posteriores à data de publicação do texto de Lutero.

\section{"Eu" versus "eles"}

A Carta de Lutero é um texto pessoal, mais que isso, é um texto basicamente em primeira pessoa. Cerca de $45,4 \%$ dos pronomes empregados (considerando os pessoais e possessivos) são relativos à primeira pessoa do singular. Logo no $3^{\circ}$ parágrafo, o autor enfatiza essa pertinência: ...ich, $D$. Luther, (“...eu, Dr. Lutero”).

A Carta apresenta ainda desde o seu início uma contraposição de ideias: as dele, Lutero, contra a dos Papistas (seguidores do Papa). O substantivo Papisten é citado já no $2^{\circ}$ parágrafo, e a partir daí a grande maioria das menções a sie (no nominativo, e variantes sie, acusativo, ihnen, dativo, e ihr*, possessivo) se dirige aos adversários do Reformador. O percentual de ocorrência dos pronomes referentes à terceira pessoa do plural é de $21,1 \%$, o segundo mais frequente.

Por várias vezes, a dicotomia "eu" versus "eles" se faz presente. De modo exemplar, lê-se no $8^{\circ}$ parágrafo:

Sie sind Doktores? Ich auch! Sie sind gelehrt? Ich auch! Sie sind Prediger? Ich auch! Sie sind Theologen? Ich auch! Sie sind Disputatoren? Ich auch! Sie sind Philosophen? Ich auch! Sie sind Dialektiker? Ich auch! Sie sind Legenten? Ich auch! Sie schreiben Bücher? Ich auch! 
Eles são doutores? Eu também. Eles são eruditos? Eu também. Eles são pregadores? Eu também. Eles são teólogos? Eu também. Eles são argumentadores? Eu também. Eles são filósofos? Eu também. Eles são dialéticos? Eu também. Eles são preletores? Eu também. Eles escrevem livros? Eu também (LUTHER, 2006a, \$8).

É também de se notar que o uso de pronomes da $1^{a}$ pessoa do singular é muito mais frequente na parte que corresponde à resposta às críticas da tradução, referentes à primeira questão (Sola / Allein). Nessa parte (19 parágrafos, do 3 ao 21), há 175 ocorrências de ich e variantes, com uma média de 9,2 por parágrafo. Na segunda parte referente à primeira questão e na segunda questão (intercessão dos santos), correspondentes, respectivamente a 6 ou 8 parágrafos, há somente 12 ou 15 citaçóes de pronomes referidos à primeira pessoa do singular, ou seja, uma média de 2,0 ou 1,9 por parágrafo. Deduzse daí que a discussão fundamental do texto é de fato a questão tradutológica ligada ao uso da palavra "somente" no contexto da salvação pela fé.

$\mathrm{Na}$ segunda questão (a dos santos), Lutero parece se abster inicialmente de um debate mais pessoal. Na parte do texto que marca o começo da discussão da segunda questão (parágrafos 23 a 25), ele não usa ich em nenhuma oportunidade.

\section{"Ele" sou "eu"}

Por vezes, Lutero se refere a ele próprio como se fosse uma terceira pessoa. Isso ocorre nos parágrafos 6 (3 vezes), 7 (3 vezes), 8 (1 vez), 10 (1 vez), 15 (1 vez). Como exemplos:

Mir ist indes genug und bin froh, daß meine Arbeit [...] muss auch durch meine Feinde gefördert und des Luthers Buch ohn Luthers Namen unter seiner Feinde Namen gelesen werden.

Entrementes, para mim é o bastante e estou contente que meu trabalho [...] seja também fomentado por meus inimigos, e o livro de Lutero sem o nome de Lutero seja lido sob o nome de seus inimigos (LUTHER, 2006a, \$7).

Luther will's so haben und spricht, er sei ein Doktor über alle Doktor im ganzen Papsttum.

"Lutero quer mantê-la assim e diz que é doutor acima de todos os doutores do papado inteiro." (LUTHER, 2006a, \$10).

Talvez o faça por motivos estilísticos, para não repetir demasiadamente a primeira pessoa. Talvez queira se colocar acima ou externamente a uma situação, como se fosse uma ideia compartilhada por seus simpatizantes. 


\section{Quem somos "nós"?}

Lutero emprega o pronome wir (e suas variantes) com distintas conotaçôes ao longo da Carta. Por vezes, "nós" assume um caráter genérico:

... weil wir lesen, daßsogar die Engel für uns bitten...

“... porque lemos que até os anjos intercedem por nós..." (LUTHER, 2006a, \$2).

... daß wir durch den Glauben an Christum, ohn alle Werke des Gesetzes gerecht werden.

"... que nós somos salvos pela fé em Cristo, sem qualquer obra da lei." (LUTHER, 2006a, \$22).

Já em outras passagens, o pronome remete a um trabalho em conjunto, em particular ao ofício de traduzir:

Im Hiob arbeiteten wir also, Magister Philips, Aurogallus und ich, daß wir in vier Tagen zuweilen kaum drei Zeilen konnten fertigen.

"Em Jó trabalhamos o mestre Philipp, Aurogallus e eu, e, às vezes, em quatro dias conseguíamos aprontar apenas três linhas." (LUTHER, 2006a, \$11).

... wo wir haben müssen schwitzen und uns ängsten, ehe denn wir solche Wacken und Klötze aus dem Wege räumeten, auf daß man könnte so fein dahergehen.

"... onde tivemos que suar e nos angustiar até tirarmos os paus e as pedras do caminho para que se pudesse prosseguir tão bem." (LUTHER, 2006a, \$11).

Por fim, Lutero emprega "nós" ao se referir a seus seguidores de fé:

Lieber, gerade Sankt Paulus und wir wollen solch Ärgernis haben... "Meu caro, precisamente São Paulo e nós desejamos tais escândalos..." (LUTHER, 2006a, \$24).

Wir wissen alle sehr wohl, was wir tun sollen. (LUTHER, [s. d.], \$30). Sabemos todos muito bem o que devemos fazer. ${ }^{4}$

${ }^{4}$ Tradução do autor. 
Deve-se notar que esse último uso dos pronomes da primeira pessoa do plural se concentra na parte do texto referente à segunda questão (intercessão dos santos). Precisamente nos parágrafos 28 a 35, wir e variantes aparecem 26 vezes (de um total de 56), correspondendo a $46 \%$ das ocorrências. Nesse trecho, não há a dicotomia entre o pensamento de Lutero e o de seus opositores, como no caso da primeira questão. Em contraste, a questão de fé é analisada entre correligionários.

\section{Papistas $=$ asnos}

Lutero introduz um insulto ao se referir aos Papistas como asnos. Tal referência sarcástica é característica de sua obra, desde 1518, direcionada a todos que se lhe opunham no caminho (BOCQUET, 2000). Na Carta, em particular, essa denominação não poderia ser mais direta, como definida no parágrafo 8:

Doktor Martinus Luther will's so haben, und spricht: Papist und Esel sei ein Ding.

"o doutor Martinho Lutero quer assim e diz que papista e asno é a mesma coisa”. (LUTHER, 2006a, \$8).

No total há 21 citações envolvendo o termo Esel (e variantes Eselskopf, Papstesel, Maulesel), quase sempre no plural, como se fora um pseudopronome sie, usado de modo depreciativo. A esse propósito, a associação do pronome "eles", se referindo aos Papistas, é carregado sempre de conotações negativas ao longo do texto:

...sie aus meinem Dolmetschen und Deutsch lernen deutsch reden und schreiben...

“...eles aprendem a falar e a escrever em alemão a partir de minha tradução e de meu alemão...” (LUTHER, 2006a, \$3).

...sie haben noch immer zu lange Ohren dazu und ihr "lka, Ika" ist zu schwach, um über mein Verdolmetschen zu urteilen.

"...eles ainda têm orelhas muito longas e seu zurro é muito fraco para julgar minha tradução.” (LUTHER, 2006a, \$4).

Ich kann Psalmen und Propheten auslegen; das können sie nicht. Ich kann dolmetschen; das können sie nicht. Ich kann beten, das können sie nicht.

"Eu sei interpretar os salmos e os profetas; eles não sabem. Eu sei traduzir; eles não sabem. Eu sei rezar; eles não sabem.” (LUTHER, 2006a, \$9). 
De fato, é admirável que, após nomear tantos insultos dirigidos aos seguidores do Papa, Lutero não tenha sido mais uma vítima da Inquisição, tendo sido somente excomungado. Por muito menos, vários opositores da Igreja, contemporâneos dele, foram condenados à fogueira. Lutero foi exilado por influência de seus protetores, príncipes alemães, e prosseguiu com suas pregações. Muitas das ideias de Lutero refletiam os interesses da nobreza alemã, revoltada com a submissão ao Papa e, principalmente, com o fato de terem que enviar riquezas a Roma. Assim, Lutero e suas ideias sobreviveram (SCHWIEBERT, 1950).

\section{Os pseudônimos}

Lutero se refere por vezes nominalmente a seus inimigos, mas usa pseudônimos ao invés dos nomes verdadeiros. $\mathrm{O}$ mais notório é o "embusteiro de Dresden” (der Sudler zu Dresden), citado nos parágrafos 6 e 7:

Denn wir haben ja gesehen den Sudler zu Dresden, der mein Neues Testament gemeistert hat (ich will seinen Namen in meinen Büchern nicht mehr nennen; zudem hat er auch nun seinen Richter und ist sonst wohl bekannt).

"Pois já vimos o embusteiro de Dresden, que se apropriou de meu Novo Testamento (não quero mais mencionar seu nome em meus livros; ademais, ele também tem agora seus juízes e é bem conhecido).” (LUTHER, 2006a, \$6).

Tal personagem é identificado como sendo Hieronymus Emser (14771527), o qual, segundo Lutero, foi um plagiário de sua tradução alemã das Escrituras. Do ponto de vista da Igreja de Roma, Emser estabeleceu a verdade original do Novo Testamento. A realidade, como sempre, é um tanto mais complexa (BOCQUET, 2000).

Mais adiante, Lutero se refere a outros dois adversários, respectivamente, Johann Faber (1478-1541) e Johann Cochläus (1479-1552), de modo irônico e insultuoso (LUTHER, 2006b):

Denn es sind solche unverschämte Tröpfe unter ihnen, die auch ibre eigene, der Sophisten Kunst nie gelernt haben, wie Doktor Schmidt und Doktor Rotzlöffel und seinesgleichen

"Pois entre eles há uns patetas descarados que nunca aprenderam nem sua própria arte, a dos sofistas, como o doutor Schmidt e o doutor Rotzlöffel e seus semelhantes...” (LUTHER, 2006a, \$6). 
Os insultos se concentram basicamente na parte do texto referente à discussão sobre a tradução dos termos sola / allein (parágrafos 3 a 21), o que corresponde também ao uso do pronome sie e seus assemelhados.

\section{"Tu" versus "vós"}

$\mathrm{Na}$ sociolinguística, uma distinção T-V (do latim tu-vos) descreve a situação na qual uma língua tem pronomes de segunda pessoa que se distinguem por nível de polidez, distância social, cortesia, familiaridade ou insulto em relação à pessoa com quem se fala (CRYSTAL, 1998).

Por exemplo, no português brasileiro contemporâneo, "você" se usa como tratamento informal e "o senhor" ou "a senhora" se referem a um discurso formal. No português arcaico e literário, as formas usuais no singular eram "tu" e "vós".

Analogamente, em alemão atual, usa-se $d u$ como equivalente de "você" e Sie para "o/a senhor(a)". À época de Lutero, no século XVI, havia uma diferenciação de tratamentos com o uso de $d u$ ("tu", informal) ou ihr (formal), equivalente ao arcaico "vós" em português. $\mathrm{Na}$ Carta, Lutero utiliza tanto $d u$ (incluindo variantes dich, dir e dein *) quanto ihr (com variantes euch e eur*).

O tratamento formal se reserva ao destinatário da Carta, o famoso Sr. N.:

Ich habe eure Schrift empfangen mit den zwo Quästionen oder Fragen, darin ihr meines Berichts begehrt...

"Recebi sua carta com as duas questões ou perguntas, sobre as quais solicita minha posição..." (LUTHER, 2006a, \$2)

Zum zweiten könnt ihr sagen, daß ich das Neue Testament verdeutscht habe...

"Por outro lado, podem dizer que eu traduzi o Novo Testamento..." (LUTHER, 2006a, \$4). ${ }^{6}$

O emprego de $d u$ tem, algumas vezes, um valor generalizante ou coletivo no texto de Lutero (BOCQUET, 2000):

\footnotetext{
${ }^{5}$ Aqui o tradutor preferiu a forma de tratamento formal atual em português, "o senhor", subentendida pelo emprego do pronome "sua" e pelo sujeito oculto: "[o senhor] solicita..." ao invés da forma arcaica "vós" e suas respectivas variantes.

${ }^{6}$ Aqui o tradutor empregou o sujeito oculto correspondente à segunda pessoa do plural: "[os senhores ou vocês] podem dizer...”.
} 
...so wirst du sehen, wer in allen beiden der Dolmetscher sei.

“... e [você] verá quem é o tradutor de ambos.” (LUTHER, 2006a, $\$ 7)$.

Hast du allein geschrieben und nicht durchgelesen?

“Apenas escreveste e não leste?” (LUTHER, 2006a, \$12).

Em outras vezes, aplica-se $d u$ a referências bíblicas, sejam elas de versões anteriores a Lutero ou a suas próprias traduções:

Gegrüßet seist du, Maria voll Gnaden, der Herr mit dir.

"Ave Maria, cheia de graça, o Senhor é contigo." (LUTHER, 2006a, $\$ 16)$.

Gott grüße dich, du liebe Maria.

“Deus te saúda, querida Maria." (LUTHER, 2006a, \$16).

É de se notar, no entanto, que a frequência de emprego dos pronomes de segunda pessoa é relativamente baixa quando se compara, por exemplo, aos de terceiro pessoa do plural. Du e variantes aparecem 28 vezes $(6,1 \%$ do total) e $i$ hr e variantes são mencionados apenas 12 vezes (12,6\% do total). Isso leva a crer que o destinatário da Carta não é uma pessoa diretamente, mas várias terceiras pessoas. Se houvesse um claro interlocutor, esses números seriam, sem dúvida, maiores.

\section{Considerações finais}

Com base na análise da frequência do uso de pronomes e de seu emprego qualificado em diversas situações, conclui-se que a Carta aberta sobre a tradução não tem um destinatário apenas, mas vários que se destacam ao longo do texto. Na parte referente à discussão sobre a justificativa pela fé e o uso do termo sola / allein há claramente um debate de ideias entre Lutero e seus opositores ("eu" contra "eles"). Já na parte referente à questão sobre a intercessão dos santos, o texto se dirige prioritariamente aos seus seguidores (prevalência no uso de "nós" e ausência significativa de "eles"). O domínio da linguagem, da técnica de tradução e da doutrina teológica refletem as características que fizeram de Lutero um pensador único, cujos princípios e métodos se mantêm relevantes e atuais. 


\section{Agradecimentos}

À Profa. Andréia Guerini (PGET/UFSC), pela oportunidade de continuar aprendendo, e ao Prof. Mauri Furlan (PGET/UFSC), pelas valiosas discussões.

\section{Referências}

BAINTON, R. Here I stand: a life of Martin Luther. New York: Penguin, 1995. BOCQUET, C. L'art de la traduction selon Martin Luther ou lorsque lê traducteur de fait missionnaire. Arras Cedex: Artois Presses Université, 2000.

BOWEN, M. Geschichte des Dolmetschens. In: Handbuch Translation. Stauffenburg: Tübingen, 1999. p. 43-46.

BRECHT, M. Martin Luther. Trad. James L. Schaaf. Philadelphia: Fortress Press, 1993.

CRYSTAL, D. T or V? In: The Cambridge Encyclopedia of Language. 2. ed. New York: University of Cambridge, 1998. p. 45.

FURLAN, M. La retórica de la traducción en el renacimiento. Tesis doctoral. Barcelona: Universitat de Barcelona, 2002. p. 237-270.

GARCIA YEBRA, V. Lutero, traductor y teórico de la traducción. Arbor, ciência, pensamiento y cultura, v. 102, n. 399, p. 23-34, 1979.

LUTHER, M. Senbrief vom Dolmetschen. In: D. Martin Luthers Werke. v. 30/ II. Weimar: Hermann Böhlaus Nachfolger, 1909. p. 632-646.

LUTHER, M. Carta aberta sobre a tradução. Trad. Mauri Furlan. In: FURLAN, M. (Org.). Clássicos da teoria da tradução. Antologia bilíngue. v. 4, Renascimento. Florianópolis: UFSC, Núcleo de Pesquisas em Literatura e Tradução, 2006a. p. 91-115.

LUTHER, M. Comentários sobre os salmos e os motivos da tradução. Trad. Raquel Abi-Sâmara. In: FURLAN, M. (Org.). Clássicos da teoria da tradução. Antologia bilíngue. v. 4, Renascimento. Florianópolis: UFSC, Núcleo de Pesquisas em Literatura e Tradução, 2006b. p. 133-159.

LUTHER, M. Sendbrief vom Dolmetschen. Versão de Radim Sochorek. [s. d.] Disponível em: <http://www.sochorek.cz/archiv/werke/luther.htm>. Acesso em: nov. 2009.

SCHWIEBERT, E.G. Luther and his times: the reformation from a new perspective. St. Louis: Concordia Publishing House, 1950.

Recebido em abril de 2010. Aprovado em maio de 2010. 